\title{
Large-scale model tests and plastic analysis of multibay infilled frames
}

\author{
K. H. Kwan, C. Q. Lo and T. C. Liauw
}

\section{Dr P. C. Pandey, Indian Institute of Science, Bangalore}

The experimental investigation presented in the Paper is limited to single-bay two-storey to two-bay two-storey infilled frame models with steel frames and concrete infills. In some of the models, the Authors have also provided shear connectors. The models are subjected to monotonically increasing lateral point load at the top corner in each case. The Authors have mentioned (\$ 8) the instrumentation adopted for measuring applied load, deflexions and stresses. I wonder if any attempt was made to measure contact stresses between the frame and the infill? If yes, is the distribution assumed in the Authors' proposed plastic analysis in agreement? If not, the basis of assumed contact stress distribution must be fully justified for a general practical situation, as it forms the backbone of their proposed plastic analysis. The discrepancy $(\S 47)$ in the observed behaviour and the prediction using the Authors' plastic theory could to some extent be attributed to their basic assumption about the interface stress distribution.

52. In the case of non-integral infilled frames subjected to monotonically increasing loads, the interface conditions between frame and infill would change. This would also have influence on the orientation of principal planes in the infill. I wonder if such observation was made from the recorded stress values ( $(9)$. Additional information that gives principal stress trajectories at typical loading increments showing the rotation of principal directions could provide further insight into the behaviour.

53. With reference to $\S 15$, the collapse modes observed both for integral and non-integral frames are found to be identical. However, this observation cannot be generalized, as it would very much depend on the nature of shear-connectors with regard to their strength and distribution along the interface.

54. The selection, design and behaviour of shear connectors, and their influence on the stiffness of infilled frames, are matters for further investigation. I have been involved in the past in such an investigation, and have observed that even a few shear-connectors that are properly designed and intermittently placed along the interface can generate the lateral stiffness of infilled frames as high as $75-80 \%$ of that of fully integral/fully bonded situations. This was an interesting observation, and I feel that such intermittent shear-connectors can provide a simpler and more cost-effective solution to enhance the lateral stiffness of infilled frames.

55. Hence, in the present context, the ultimate behaviour of such infilled frames with intermittent shear-connectors would obviously be different from nonintegral infilled frames and they cannot be grouped together for the purpose of

Paper published: Proc. Instn Civ. Engrs, Part 2, 1990, 89, June, 261-277. 


\section{DISCUSSION}

analysis. Further experimental study on the collapse phenomena similar to the one carried out by the Authors would be desirable before the collapse modes are postulated.

56. With reference to $\$ 19-21$, I have similar reservations to those expressed by May et al. ${ }^{18,19}$ in their earlier discussions. However, in respect of an infilled frame with a gap at the top, other mechanisms of collapse are possible (one such mode could be the combination of the Authors' modes 1 and 3).

57. In a general practical situation, there would, in addition to the lateral loading, also be vertical loading transmitted on to the floor beams which would influence the length of the contact zone and contact stress distribution between frame and infill. This obviously limits the validity of the Authors' analytical approach.

58. In addition, there are several practical aspects which would depend on the nature of construction of a filled frame. The materials of the frame (e.g. steel, concrete) and infill (e.g. concrete, conventional burnt clay brick, and new construction materials such as hollow-core concrete blocks, soil-cement pressed brick), size and location of openings in the infill, nature of infilling in the adjacent panels, base support conditions, etc., would have significant influence on the ultimate response of the structure. It would be quite cumbersome to present a unified plastic theory to accommodate these aspects. This would perhaps also explain the discrepancy in the Authors' experimental observation and theoretical prediction mentioned in $\S 47$.

59. The Authors' mixed computational-analytical procedure suggested in $\S 44$ has limitations and can be a source of error; from the user's point of view, it lacks clarity and practicability. Some experimental observations - made recently by, for example, Dawe and $\mathrm{Seah}^{20}$ - cannot be accommodated convincingly in the Authors' approach. I feel that a non-linear finite-element procedure, with suitable constitutive models and proper interface modelling, would be a better alternative with which to carry out a complete analysis in a realistic way. Perhaps one can try to improve the predictions by implementing adaptivity ${ }^{21}$ in mesh refinement in the non-linear analysis.

\section{Dr Kwan, Dr Lo and Professor Liauw}

It should be noted at the very outset that the plastic analysis employed in the Paper has been correlated not only to experimental results but also to non-linear finite-element analysis, which Dr Pandey prefers. However, we do not subscribe to the narrow view that only a certain approach to the problem of infilled frames is superior, as is implied by Dr Pandey in his preference for non-linear finite-element analysis (§59) and by May et al. ${ }^{18.19}$ in their preference for empirical approach. The sad aspect about some investigators with a narrow view is that they exhibit the limitations of their perception in overlooking the constraints/disadvantages in their preferred approach as much as the applicabilities/advantages in approaches proposed by others.

61. As Dr Pandey praises the non-linear finite-element method, we should like to draw his attention to the fact that we were actually the first to employ the non-linear finite-element method to study the failure characteristics of infilled frames. Our earliest application of the non-linear finite-element method to infilled frames dates back to $1982 .{ }^{3}$ We have for many years been using this rather elaborate method as a research tool to study the non-linear behaviour of infilled 
frames. ${ }^{10,11,13,14}$ However, we are of the opinion that in actual structural design applications, the plastic theory, which allows more direct evaluation of the collapse loads and does not require expensive facility and expertise for large-scale numerical computations, is more suitable. ${ }^{22}$

62. No attempt to measure the contact stresses between the frame and the infill was made in this project. In another joint project conducted by Professors Liauw and Hendry at the University of Edinburgh, such an attempt was made using small dismountable transducers, but the readings obtained were very random. However, the justification of the assumed contact stress distribution has been derived from the results of non-linear finite-element analysis, ${ }^{10,11}$ as mentioned in $\$ 21-23$.

63. With reference to $\S 52$, full details of the principal stress trajectories at various load levels will be published in a later paper. Similar information but on smaller scale models has been published in references 3,13 and 14 .

64 . With regard to the comments in $\$ 53$ and 55 , it was only coincidential that the collapse modes observed in the particular integral and non-integral infilled frame models tested were identical. The actual collapse mode is dependent on the model parameters and, in general, the collapse mode of an integral infilled frame may be different from that of a non-integral infilled frame. We did not generalize that the collapse modes of integral and non-integral infilled frames should be identical, and Dr Pandey has apparently misconceived our statement of facts.

65. With reference to $\S 54$, we concur with Dr Pandey that the provision of even some intermittent shear connectors could significantly increase the stiffness and strength of the infilled frames, and that the shear connectors are very costeffective. Our experience has demonstrated that shear connectors amounting to only about $6 \%$ by weight of that of the frame would be more than sufficient to utilize fully the shear strength of the concrete at the infill/frame interface. ${ }^{11}$

66. In response to $\S 56$, we wish to point out that we had not ruled out other possible collapse modes. In the discussions of results in $\S 48$, we did suggest that there may be collapse modes other than those observed in the large-scale model tests. Further research is required to identify the other collapse modes.

67. Dr Pandey has rightly pointed out in $\$ 57$ that any vertical loads transmitted from the floor beams may affect the length of contact and stress distribution at the beam/infill interface. Therefore, if the vertical loads transmitted from the floor beams are significant, one needs to be more careful in applying the plastic theory, although the Authors trust that the negligence of the extra contact stresses at the beam/infill interface due to the vertical loads should be on the safe side, provided that the effects of the vertical axial loads on the plastic moments of the columns are taken into account. However, we are not aware of any other method, except the rather involved non-linear finite-element method, which can allow for the vertical load effects. Some further studies on this problem are necessary before the full effects of the vertical loads can be taken into account without use of the non-linear finite-element method.

68. With reference to $\$ 58$ and 59 , it should be noted that the proposed plastic theory was developed originally for concrete infilled frames only, not for masonry (brickwork or blockwork) infilled frames. The obvious reason is that our plastic theory was developed on the basis of the results of our non-linear finite-element analysis $3,10,11$ which was applicable only to concrete infilled frames. The nonlinear finite-element analysis of masonry infilled frames requires an appropriate material modelling for the brickwork/blockwork which is much more complicated 


\section{DISCUSSION}

than that of concrete. Nevertheless, we have been working for several years towards the development of a new non-linear finite-element method for the analysis of masonry infilled frames. It somehow turns out to be a rather difficult task and it may be some more years before a plastic theory for masonry infilled frames can be developed. We have also carried out some large-scale model tests of masonry infilled frames (the results will be published in a later paper). A preliminary conclusion which can be made at this stage is that masonry infilled frames behave quite differently from concrete infilled frames. No single theory could be applicable to both concrete and masonry infilled frames.

69. With regard to Dr Pandey's suggestion of implementing adaptivity in the non-linear finite-element analysis, we wish to comment that this would not help to understand better the non-linear behaviour of the structures, although it may improve the computational efficiency of the method.

\section{References}

18. May I. M. et al. Discussion on reference 5. Proc. Instn Civ. Engrs, Part 2, 1984, 77, June, 279-286.

19. MaY I. M. et al. Discussion on reference 6. Proc. Instn Civ. Engrs, Part 2, 1984, 77, Sept., 413-418.

20. Dawe J. L. and Seah C. K. Behaviour of masonry infilled steel frames. Can. J. Civ. Engng, 1989, 16, No. 6, 865-876.

21. ZIENKIEWICZ O. C. and TAYLOR R. L. The finite element method. McGraw-Hill, 1989, 4th edn, I.

22. Liauw T. C. and Kwan K. H. Plastic design of infilled frames. Proc. Instn Civ. Engrs, Part 2, 1984, 77, Sept., 367-377. 